\title{
Cancer Stem Cells - Therapeutic Boon!
}

\section{Shrihari TG*}

Department of Oral Medicine and Radiology, Krishnadevaraya dental college and hospital, India

\begin{abstract}
Cancer stem cells (CSC) are recently proposed to be the cancer initiating cells responsible for tumorigenesis and contribute to cancer resistance. Like normal stem cells, cancer stem cells should be rare, quiescent and capable of self renewing \& maintaining tumor growth and heterogeneity. Although the concept of cancer stem cells originates from that of normal stem cells, cancer stem cells are not necessarily aberrant counterparts of normal stem cells. In fact, they may arise from stem cells or committed progenitors of corresponding tissues \& even cells from other tissues. At the molecular level, the alteration of stem cell self-renewal pathways has been recognized as an essential step for cancer stem cells transformation. Better understanding of cancer stem cell will no doubt lead to new era of both basic \& clinical research, reclassification of human tumors \& development of novel therapeutic strategies specifically targeting cancer stem cells.
\end{abstract}

Keywords: Tumor stem cells; Aldehyde dehydrogenase (ALDHs); Melanoma chondroitin sulphate proteoglycans(MCSP); ATP binding cassette (ABC); Microtubule associated protein (MAC)

\section{Introduction}

Stem cells are defined as cells that have the ability to perpetuate themselves through self renewal and to generate mature cells of a particular tissue through differentiation. In most tissues, stem cells are rare. As a result, stem cells must be identified prospectively \& purified carefully in order to study their properties [1,2].Here we discuss emerging evidence that stem cell biology could provide new insights into cancer biology .In particular, we focus on three aspects of the relationship between stem cells and tumor cells. First, the similarities in the mechanisms that regulate self renewal of normal stem cells \& cancer cells; second the possibility that tumor cells might arise from normal stem cells \& third, the notion that tumors might contain 'cancer stem cells' - rare cells with indefinite proliferative potential that drive the formation \& growth of tumors [3,4].

\section{Identification \& isolation of tumor stem cells}

Tumor stem cells were first isolated as clones based on the soft agar cloning technique. However, this technique is time and labor intensive and only a small fraction of primary tumors yield adequate numbers of colonies [5]. An alternative is to culture tumor stem cells as floating spheres.

More recently, relatively undifferentiated tumor stem cells sphere culture have been derived from primary tumors \& cell lines using serum- free medium that is supplemented with growth factors, such as epidermal growth factor \& basic fibroblast growth factors. Serum replacement results in the morphological change of adherent monolayer culture to tumor stem cells - enriching floating spheres, such as neurospheres [6].

\section{Cell surface markers}

Cell surface proteins, such as CD24, CD44, CD133 \& integrins, to name a few, have been used as tumor cell markers. CD133 is discussed briefly as it will be used several times to highlight various themes in tumor stem cells research. CD133 is a transmembrane glycoprotein that has been reported as a tumor stem cell marker for breast, lung, liver, colon, prostate \& brain tumors [7-10].
Although CD133 expression might point to a possible tumor stem cell, it is not a reliable marker due to the technical limitations of its detection \& due to inherent tumor stem cell heterogeneity resulting in cellular subsets within a tumor stem cell population. CD133 expressing cells have been identified \& isolated using the monoclonal antibodies AC133 \& AC141. Tumorstem cell heterogeneity within a particular tumor appears to hinder the use of a single marker for reliable tumor stem cell identificatios [11].

\section{Enzyme markers}

Aldehyde dehydrogenase has been reported as a tumor cell marker. ALDHs catalyze the oxidation of a wide variety of aldehydes to carboxylic acids \& are known to play an important role in endobiotic \& xenobiotic metabolism. Accordingly, ALDHs have been known to provide resistance to hematopoietic stem cells against alkylating agents of the oxazophosphorins family, such as cyclophosphamide \& its derivatives. Based on the broad utility of ALDHs, methods to detect ALDH activity have been commercially developed, such as the aldefluor assay \& have been used to sort cells with variant ALDH activity.

ALDH isozymes have been reported as Tumor stem cell markers in pancreatic cancer, Breast cancer, prostate cancer, lung cancer, multiple myeloma \& leukaemia. Although ALDH activity may indicate potential tumor stem cells, there are draw backs to its utility as a marker $[8,12,13]$.

\section{Gene expression profiles}

Cell surface \& enzymatic molecules offer practically use full tumor stem cells markers. However, they do not provide a comprehensive view of the molecular pathways operating in tumor stem cells. Together this information, genetic profiling has been used. Human prostate tumor

${ }^{*}$ Corresponding author: Shrihari TG, PhD, Assistant Professor, Department of Oral Medicine \& Radiology, Krishnadevaraya dental college and hospital, Bangalore -562157, Karnataka, India, E-mail: drshrihariomr@gmail.com

Received June 15, 2011; Accepted September 27, 2011; Published September 29, 2011

Citation: Shrihari TG (2011) Cancer Stem Cells - Therapeutic Boon! J Cancer Sci Ther 3: 197-200. doi:10.4172/1948-5956.1000088

Copyright: @ 2011 Shrihari TG. This is an open-access article distributed under the terms of the Creative Commons Attribution License, which permits unrestricted use, distribution, and reproduction in any medium, provided the original author and source are credited. 
stem cells were isolated based on the cell surface signature $\mathrm{CD} 133^{+}$, subjectively these were subjected to expression analysis \& compared to their normal \& differentiated counterparts. The gene expression profile of these tumor stem cells provided a signature consisting of significantly variable expression of 581 genes. These variable gene expressions were used for functional annotation of the signature. This pointed to various pathways involved in TSC biology. JAK- STAT signalling, cell adhesion \& extracellular matrix interactions, focal adhesion signalling \& Wnt signalling. These are some of the pathways that could be targeted to deplete tumor stem cells [14].

\section{Functional markers}

Although cell surface molecules, enzymes \& genetic profiles have been used to identify potential tumor stem cells, a more reliable proof may be based on functional tumor stem cell markers. These include invitro (Proliferation, Colony forming capability, adhesion, migration \& invasion) \& in vivo (tumorigenicity, metastatic capability \& ability to recapitulate the morphological features of specific tumor) $[6,12]$.

\section{Drug resistance in tumor stem cells}

After initial response to chemotherapy, relapse is often observed. This has been attributed to the existence of drug- resistant TSCs in a variety of tumors, such as breast tumor and osteosarcoma $[15,16]$. Various mechanisms known to confer longer life span to stem cells have been speculated to contribute to drug resistance in TSC. These mechanisms might involve relative quiescence, expression of multidrug resistant proteins, robust DNA repair capability and effective strategies to avoid apoptosis $[17,18]$.

\section{Quiescence}

The TSC niche has been envisioned as a modulator of TSC quiescence. It has been suggested that there might be two types of TSC niches. One that maintains quiescence \& another that maintains proliferative cells [19]. Tumors are known to grow in hypoxic environment. Hypoxia induces production of H1F1 alfa \& H1F12 alfa. These H1F1 alfa can exert opposite effects on proliferation [20]. For example, H1F1alfa inhibits C-myc \& mTOR and activates $\mathrm{P}^{53}$; thus decreases proliferation. H1F2 alfa activates C-myc \& mtor \& inhibits $\mathrm{P}^{53}$; thus increases proliferation [21]. Further understanding of the molecular regulation of quiescence has been gained from gene expression profiling of TSCs enriched based on higher Beta -1 integrin expression in sqamous cell carcinoms [22]. Among various markers that were examined, the ones that correlated with diminished differentiation status \& increased proliferation were - Lewin-rich repeats and immunoglobulin like domains 1 (Lrig 1) \& microtubuleassociated protein 4 (MAP4) (down regulated) \& melanoma chondroitin sulphate proteoglycan (MCSP) (upregulated). Lrig1 negatively regulates epidermal growth factor receptor signalling. Thus it maintains epidermal stem cells in a quiescent state [22-25].

It's down regulation would perturb the quiescence \& aid in proliferation of TSCs. MAP4 has been reported to be involved in the regulation of cell cycle progression \& cytokinesis [22,26]. Thus, although requiring further proof, it has been suggested that down regulation of MAP4 could enhance cell cycle progression of TSCs [22].

MCSP has been known to stimulate integrin mediated adhesion \& spreading of tumor cells by activating the small GTPases CDC42 \& RAC1 $[22,27,28]$. Thus up regulation of MCSP would favour metastatic potential of TSCs [22].
Various aspects governing the TSC niche \& new new therapeutic strategies against the quiescent cells in the niche have recently been reviewed [29]. It is difficult to recapitulate the various factors operating in the in vivo TSC niche in an invitro culture system. However, it is important to decipher the molecular cues that govern quiescence, proliferation and metastasis as these may modulate TSC longevity \& tumor relapse.

\section{Enhanced DNA repair}

DNA damage can be fatal for rapidly dividing tumor cells. In this regard, alkylating agents, such as temozolomide and carmustine, have been used to induce DNA damage for glioma Chemotheraphy. However, TSCs that initiate \& sustain tumors might have enhanced DNA repair mechanisms, which can resolve the alkylation damage to DNA. Furthermore, TSCs might have a higher tolerance limit for mutations due to defects in apoptosis machinery [30].

\section{Antiapoptotic characteristics}

Apoptosis can effectively remove damaged or potentially harmfull cells by extrinsic and intrinsic pathways. As noted above, CD44 has been used as a TSC marker. CD44 perturbs the Fas -based extrinsic apoptotic pathway, thus aiding in longer TSC life span. Also, TSCs have been observed to express higher levels of anti-apoptotic genes such as FLIP, BCL-2, BCL-XL \& IAP family members [31,32]. Taken together, experimental evidence suggests that TSCs have evolved strategies to evade death mechanisms. The understanding of the underlying molecular pathways may provide potential therapeutic opportunities to achieve targeted TSC ablation.

\section{Therapies against TSCS}

To achieve tumor eradication, it is thought to be essential to target TSCs. A variety of molecules \& pathways operating in TSCs could potentially be targeted with therapeutic molecules. Tumor stem cells may display multidrug resistance that is conferred by $\mathrm{ABC}$ transporters [33]. Tumor stem cells may display ATP binding cassette (ABC) transporters have been reported as TSC markers in melanoma \& osteosarcoma, among others [34,35]. Targeted inactivation of ABC transporters could reinstate the drug sensitivity in TSCs resulting in TSC killing. For example ABCB5 has been reported as a marker for a subset of $\mathrm{CD} 133^{+}$melanoma stem cells. ABCB5 provides resisstance to doxorubicin by functioning as an efflux pump. When it was blocked by anti- ABCB5 monoclonal antibody doxorubicin sensitivity was restored in these TSCs [36].

Tumor cells have been observed to reactivate telomerase to achieve immortality [37]. Increased telomerase activity has been reported in approximately 90 percent of malignant tumors [38]. Sustained telomerase function is necessary for TSCs that have the potential to proliferate indefinitely. Thus, anti-telomerase agents are expected to target tumor cells as well as TSCs. The increasing knowledge about molecular pathways governing various aspects of TSCs could be exploited to tailor drug based therapies for TSC ablation. A variety of signalling pathways, previously reported to be aberrantly modulated in TSCs. These include wnt/beta-catenin, Hedgehog, notch, JAK/STAT, PTEN/P ${ }^{13} \mathrm{k} / \mathrm{AKT}$, \& TGF-beta pathways $[14,39,40]$. These pathways in TSCS may be targeted with agents, many of which have been advanced to translational application against tumor cells. Thus, there is a possibility of using drugs already available for TSC eradication. 


\section{Future Perspectives}

Tumor stem cells are poised to play an important role in the effort to achieve successful tumor ablation. The research to understand the biology of tumor stem cells is progressing rapidly. As this knowledge become more concrete, it will pave the way for reliable TSC identification \& isolation. However, various factors may complicate TSC targeting. First, TSCs appear to represent heterogeneous populations. Potential sources of this heterogeneity are genetic, epigenetic and environmental factors. The constitutional genomic features of individual patients (including gene copy number differences \& single nucleotide polymorphisms, among others) as well as somatic mutations /genetic instability features contribute to TSC heterogeneity. The differentiated features of tumor stem cells may reflect the epigenetic status of cells from which the tumor arose. In addition, environmental factors, such as those operating in the TSC niche can contribute to heterogeneity. Therefore, it is unlikely that one particular targeting molecule could be used to deliver therapeutic agents to all TSCs within a single tumor. Second, TSCs reside in niches, \& the targeting agent will have to traverse the blood stream \& penetrate through cells \& tissues surrounding the niche. Finally, the biology of TSCs is still being elucidated. In the TSC niche, TSCs have complicated interactions with the surrounding stromal cells, which may modulate TSCs at the molecular level. These molecular changes may manifest as epigenetic, genetic and proteomic changes. The dynamic TSC changes and adaptations modulated in response to their microenvironment will complicate the effort to develop a TSC- targeted therapeutic agent. Tumor stem cell targeting is essential, but recently it has been speculated that non-TSCs in a tumor need to be targeted as well. These non-TSCs could form TSCs \& might even sustain the tumor even after TSCs have been destroyed [41]. After resolving the multitude of issues related to tumor stem cell culture, identification, isolation, $\&$ targeting .better treatment options may be developed. Along with the conventional treatments, new technologies, such as gene therapy \& nanotechnology [42-44], could provide Sophisticated multifunctional agents for simultaneous targeting, imaging, and therapy of TSCs.

\section{References}

1. Spangrude GJ, Heimfeld S, Weissman IL (1988) Purification and characterization of mouse hematopoietic stem cells. Science 241: 58-62.

2. Morrison SJ, Weissman IL (1994) The long-term repopulating subset of hematopoietic stem cells is deterministic and isolatable by phenotype. Immunity 1: 661-673.

3. Lagasse E, Connors H, Al-Dhalimy M, Reitsma M, Dohse M, et al. (2000) Purified hematopoietic stem cells can differentiate to hepatocytes in vivo. Nat Med 6: 1229-1234.

4. Krause DS, Theise ND, Collector MI, Henegariu O, Hwang S, et al. (2001) Multi-organ, multi-lineage engraftment by a single bone marrow derived stem cell. Cell 105: 369-377.

5. Shoemaker RH, Wolpert-DeFilippes MK, Kern DH, Lieber MM, Makuch RW, et al. (1985) Application of a human tumor colony-forming assay to new drug screening. Cancer Res 45: 2145-2153.

6. Yu SC, Ping YF, Yi L, Zhou ZH, Chen JH, et al. (2008) Isolation and characterization of cancer stem cells from a human glioblastoma cell line U87. Cancer Lett 265: 124-134.

7. Wright MH, Calcagno AM, Salcido CD, Carlson MD, Ambudkar SV, et al.(2008) Brca1 breast tumors contain distinct CD44 + /CD24) andCD133 + cells with cancer stem cell characteristics. Breast Cancer Res $10:$ R10.

8. Boman BM, Wicha MS (2008) Cancer stem cells: a step toward the cure. J Clin Oncol 26: 2795-2799.
9. Vermeulen L, Todaro M, de Sousa Mello F, Sprick MR, Kemper K, et al. (2008) Single-cell cloning of colon cancer stem cells reveals a multi-lineage differentiation capacity. Proc Natl Acad Sci U S A 105: 13427-13432.

10. Singh SK, Clarke ID, Terasaki M, Bonn VE, Hawkins C, et al. (2003) Identification of a cancer stem cell in human brain tumors. Cancer Res 63 5821-5828.

11. Bidlingmaier S, Zhu X, Liu B (2008) The utility and limitations of glycosylated human CD133 epitopes in defining cancer stem cells. J Mol Med 86: 1025 1032.

12. Croker AK, Goodale D, Chu J, Postenka C, Hedley BD, et al. (2008) High aldehyde dehydrogenase and expression of cancer stem cell markers selects for breast cancer cells with enhanced malignant and metastatic ability. J Cell Mol Med 13: 2236-52.

13. Ucar D, Cogle CR, Zucali JR, Ostmark B, Scott EW, et al. (2009) Aldehyde dehydrogenase activity as a functional marker for lung cancer. Chem Biol Interact 178: 48-55.

14. Birnie R, Bryce SD, Roome C, Dussupt V, Droop A, et al. (2008) Gene expression profiling of human prostate cancer stem cells reveals a proinflammatory phenotype and the importance of extracellular matrix interactions. Genome Biol 9: R83.

15. Li X, Lewis MT, Huang J, Gutierrez C, Osborne CK, et al. (2008) Intrinsic resistance of tumorigenic breast cancer cells to chemotherapy. J Natl Cancer Inst 100: 672-679.

16. Gillette J, Nielsen-Preiss S (2009) Cancer stem cells: seeds of growth in osteosarcoma. Cancer Biol Ther 8: 553-554.

17. Kvinlaug BT, Huntly BJP (2007) Targeting cancer stem cells. Expert Opin Ther Targets 11: 915-927.

18. Raguz S, Yague E (2008) Resistance to chemotherapy: new treatments and novel insights into an old problem. Br J Cancer 99: 387-391.

19. Sneddon JB, Werb Z (2007) Location, location, location: the cancer stem cell niche. Cell Stem Cell 1: 607-611.

20. Gordan JD, Thompson CB, Simon MC (2007) HIF and C-Myc: sibling rivals fo control of cancer cell metabolism and proliferation. Cancer Cell 12: 108-113.

21. Keith B, Simon MC (2007) Hypoxia-inducible factors, stem cells, and cancer. Cell 129: 465-472.

22. Jensen KB, Jones J, Watt FM (2008) A stem cell gene expression profile of human squamous cell carcinomas. Cancer Lett 272: 23-31.

23. Jensen KB, Watt FM (2006) Single-cell expression profiling of human epiderma stem and transit-amplifying cells: Lrig1 is a regulator of stem cell quiescence. Proc Natl Acad Sci USA 103: 11958-11963.

24. Gur G, Rubin C, Katz M, Amit I, Citri A, et al. (2004) LRIG1 restricts growth factor signalling by enhancing receptor ubiquitylation and degradation. EMBO J 23: $3270-3281$

25. Laederich MB, Funes-Duran M, Yen L, Ingalla E, Wu X, et al. (2004) The leucine-rich repeat protein LRIG1 is a negative regulator of ErbB family receptor tyrosine kinases. J Biol Chem 279: 47050-47056.

26. Andersen SS (2000) Spindle assembly and the art of regulating microtubule dynamics by MAPs and Stathmin/Op18. Trends Cell Biol 10: 261-267.

27. Eisenmann KM, McCarthy JB, Simpson MA, Keely PJ, Guan J, et al. (1999) Melanoma chondroitin sulphate proteoglycan regulates cell spreading through Cdc42, Ack-1 and p130cas. Nat Cell Biol 1: 507-513.

28. Majumdar M, Vuori K, Stallcup WB (2003) Engagement of the NG2 proteoglycan triggers cell spreading via rac and p130cas. Cell Signal 15: 79-84.

29. Iwasaki H, Suda T (2009) Cancer stem cells and their niche. Cancer Sci 100 1166-1172.

30. Johannessen TC, Bjerkvig R, Tysnes BB (2008) DNA repair and cancer stemlike cells - potential partners in glioma drug resistance? Cancer Treat Rev 34 558-567. 
31. Liu G, Yuan X, Zeng Z, Tunici P, Ng H, et al. (2006) Analysis of gene expression and chemo resistance of $\mathrm{CD} 133^{+}$cancer stem cells in glioblastoma. Mol Cancer 5: 67.

32. Jin F, Zhao L, Zhao HY, Guo SG, Feng J, et al. (2008) Comparison between cells and cancer stem-like cells isolated from glioblastoma and astrocytoma on expression of antiapoptotic and multidrug resistance-associated protein genes. Neuroscience 154: 541-550.

33. Dean M (2009) ABC transporters, drug resistance, and cancer stem cells. J Mammary Gland Biol and Neoplasia 14: 3-9.

34. Schatton T, Murphy GF, Frank NY, Yamaura K, Waaga-Gasser AM, et al. (2008) Identification of cells initiating human melanomas. Nature 451: 345-349.

35. Tirino V, Desiderio V, d'Aquino R, De Francesco F, Pirozzi G, et al. (2008) Detection and characterization of CD133 + cancer stem cells in human solid tumours. PLoS ONE 3: e3469.

36. Frank NY, Margaryan A, Huang Y, Schatton T, Waaga-Gasser AM, et al. (2005) ABCB5-mediated doxorubicin transport and chemoresistance in human malignant melanoma. Cancer Res 65: 4320-4333.

37. Harley CB (2008) Telomerase and cancer therapeutics. Nat Rev Cancer 8: 167-179.
38. Shay JW, Keith WN (2008) Targeting telomerase for cancer therapeutics. Br J Cancer 98: 677-683.

39. Bleau AM, Hambardzumyan D, Ozawa T, Fomchenko El, Huse JT, et al (2009) PTEN/PI3K/Akt pathway regulates the side population phenotype and ABCG2 activity in glioma tumor stem-like cells. Cell Stem Cell 4: 226-235.

40. Peacock CD, Wang Q, Gesell GS, Corcoran-Schwartz IM, Jones E, et al (2007) Hedgehog signaling maintains a tumor stem cell compartment in multiple myeloma. Proc Natl Acad Sci 104: 4048-4053.

41. Gupta PB, Onder TT, Jiang G, Tao K, Kuperwasser C, et al. (2009) Identification of selective inhibitors of cancer stem cells by high-throughput screening. Cell 138: 645-659.

42. Saini V, Martyshkin DV, Mirov SB, Perez A, Perkins G, et al. (2008) An adenoviral platform for selective self-assembly and targeted delivery of nanoparticles. Small 4: 262-269.

43. Saini V, Roth JC, Pereboeva L, Everts M (2007) Importance of viruses and cells in cancer gene therapy. Adv Gene Mol Cell Ther 1: 30-43.

44. Saini V, Zharov VP, Brazel CS, Nikles DE, Johnson DT, et al. (2006) Combination of viral biology and nanotechnology: new applications in nanomedicine. Nanomedicine 2: 200-206. 